Table II. - Ash and Phosphorus in Ttbercle Bacitri. ${ }^{1}$

\begin{tabular}{|c|c|c|c|c|}
\hline & $\begin{array}{l}\text { Moisture. } \\
\text { Per cent. }\end{array}$ & $\begin{array}{l}\text { Ash. } \\
\text { Percent. }\end{array}$ & $\begin{array}{l}P_{y} \mathrm{O}_{\text {in }} \mathrm{d} \text { ty } \\
\text { pacilli. } \\
\text { Per cent. }\end{array}$ & $\begin{array}{l}\mathrm{P}_{2} \mathrm{O}_{5} \text { int } \\
\text { ash. } \\
\text { Percent }\end{array}$ \\
\hline \multirow{2}{*}{ Bovine bacilli. } & $\int 2.42$ & 2.66 & I. 56 & $5^{8.54}$ \\
\hline & 2.48 & 2.67 & I. 55 & $5^{8.04}$ \\
\hline \multirow{2}{*}{ Swine bacilli. . } & 2.26 & 2.37 & 1.30 & 55.00 \\
\hline & 2.06 & $2.3 \mathrm{I}$ & 1.31 & 56.48 \\
\hline \multirow{2}{*}{ Horse bacilli. } & 2.27 & 3.63 & 2.07 & 55.68 \\
\hline & 2.42 & 3.55 & 2.02 & $55 \cdot 40$ \\
\hline \multirow{2}{*}{ Avian } & $\{2.40$ & 3.96 & 2.22 & 55.98 \\
\hline & $\ldots$ & 3.94 & 2.19 & 55.63 \\
\hline \multirow{2}{*}{ Human bacilli (atten.) } & 2.67 & 2.44 & I. 79 & $73 \cdot 49$ \\
\hline & $2.5^{8}$ & $2.3 I$ & 1.71 & $74 \cdot 3^{8}$ \\
\hline \multirow{2}{*}{ Human bacilli } & $\{3.95$ & 3.94 & 2.50 & 63.47 \\
\hline & 13.70 & 3.92 & 2.39 & 60.90 \\
\hline
\end{tabular}

'Determinations by James A. Enery.

[CONTRIBUTION FROM THE LABORATORY OF THE BUREAC OF INTERNAL REVENUE, U.S. TREASUR X DEPARTMENT.]

\title{
THE COMPOSITION OF PROCESS OR RENOVATED BUTTER.'
}

BY ChARLESA. CRAMPTON.

Recelvel , lanuary 5,1903

THE Act of May 9, I902, makes this product, as specifically defined therein, subject to Federal control, placing its production, transportation and sale under restrictions similar to those imposed upon oleomargarine, which product is also made the subject of new legislation by the same act.

Without entering into detail concerning the provisions of the new law, its main features may be briefly stated, as follows: It defines two classes of oleomargarine, one taxable at $1 / 4$ cent per pound, and the other at ro cents per pound, and three classes of butter. Of the latter, one class is normal or statutory butter, defined for purposes of comparison, and exempt, of course, from taxation or supervision; one class is "process or renovated butter," taxable at $1 / 4$ cent per pound, the same rate as that laid upon oleomargarine free from artificial coloration; and the third class is "adulterated butter," subject to a tax of Io cents per pound, the same rate as artificially colored oleomargarine.

The sale of renovated butter is not so closely regulated as that of oleomargarine, as no special tax is required from wholesale or retail dealers, so that government control does not follow it to the

1 Read at the washington meeting of the American Chemica! society. 
purchaser. The clause concerning the prohibition of ingredients deleterious to health in oleomargarine is not made applicable to renovated butter, but the manufacture of the latter product is made subject to the supervision of the Bureau of Animal Industry of the Department of Agriculture, a provision doubtless intended to serve the same purpose. Moreover, by a somewhat peculiar interweaving of definitions, renovated butter loses its status as such, and becomes "adulterated butter" under certain conditions, and is then subject to the high rate of tax imposed upon that product. During the first three months of the operation of the law, there were produced in the United States, as shown by the Annual Report of the Commissioner of Internal Revenue for I9O2, $5,879,833$ pounds of renovated butter, about one-half as much as the total quantity of oleomargarine produced during the same period.

Subject to the control of two different departments of the general government, and also to restrictive laws in many of the States, renovated butter has come to be a product of considerable interest to chemists, and it is highly desirable to obtain some knowledge of the character of the changes undergone by the butter-fat in the processes to which it is subjected by the methods employed. A brief description of the ordinary methods of renovation as practiced in most of the factories at the present time may not be amiss. The raw material or "stock," as it is termed, consists of butter which is not salable for direct consumption, either because it has deteriorated through rancidity, mold, or other causes, or because it was produced by careless or ignorant makers, who were unable to give it an attractive appearance or flavor. The country grocery store, which assembles small lots or parcels of butter from many makers, and dumps all together, indiscriminately, good, bad, and indifferent, is the recruiting ground for most of the material. In the earlier days of the industry, the stock obtainable for renovating purposes was but a shade better than the soap-fat grade, but competition has advanced the price, and the increased demand has secured a more prompt marketing of the material, so that much of it has not greatly deteriorated from its original condition when it reaches the renovating factory. The character of the renovated product has correspondingly improved, especially in its keeping qualities. The best grades approximate the lower grades of creamery butter, the chief defect 
being the loss of "grain" through the operation of melting, a quality which is only partially restored by subsequent granulation in ice water.

The first step in the process is the separation of the fat from the water and curd by melting and settling. The curd and salt water are drawn off from beneath the oil, or sometimes the whole is passed through a separator. Whatever bad flavor is inherent in the curd is separated in this operation, and the fat is ready for the next treatment, which is the aeration or "blowing" with air. This is sometimes supplemented by a bath of water, and renovators have been accused of using chemical agents at this stage of the procedure, but they claim that such treatment has not been found successful, doubtless from the tendency towards saponification, and that the main reliance is upon the blowing to remove disagreeable odors, and leave a fairly neutral fat. This is then emulsitied with fresh milk, which has been inoculated with a bacterial culture after improved creamery methods, and the whole is chilled, granulated and churned. The subsequent working of the butter and packing for market is similar in all respects to the customary treatment.

It will be seen from the above description of the method of its preparation that renovated butter cannot be expected to vary greatly from ordinary butter in its chemical composition. The only differences must arise from the substitution of a different buttermilk for that originally present, and whatever changes have been brought about in the butter-fat by the manipulations tc which it has been subjected. In the appended table I have brought together the average results of the analysis of 7.5 samples made in this laboratory during the first four months of the operation of the law. The samples were produced at licensed factories located in different parts of the United States, and were accompanied in most cases by afficlavits of the producers to the effect that the samples fairly represented their product. In other cases they were taken by government officers.

The methods of analysis used were essentially those of the Association of Official Agricultural Chemists : the Reichert-Meisslvalue was determined strictly in accordance with Wollny's procedure. as officially prescribed by the English government. ${ }^{1}$ The percentage of water was determined by difference and also by drying,

1 Analy'st, 25, 309 (rgoo). 
direct. The latter is the figure used in passing upon the liability of the butter to tax as "adulterated butter," on account of containing an excessive quantity of "water, milk or cream." The regulations fix the maximum limit at 16 per cent., following European precedent in this respect.

TABLE OF AVERAGES.

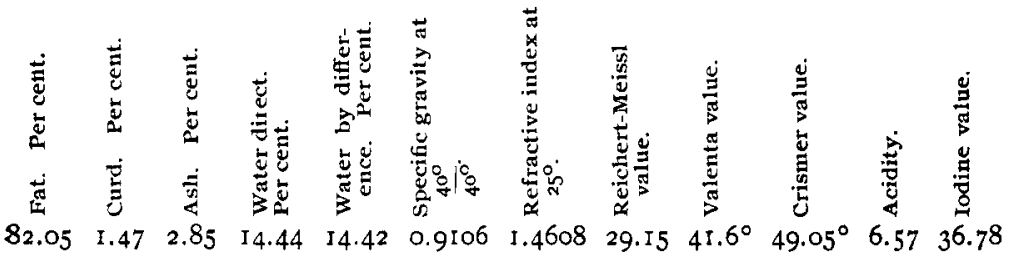

Of the above, the percentage composition figures and the refractive index and Reichert-Meissl value, represent the mean of all the samples; the specific gravity was determined upon fiftyeight only, the Crismer, Valenta and acidity values upon fiftyfour, and the iodine value upon twenty-five.

The maximum percentage of fat in any sample was 88.88 , the minimum, 68.80 ; curd, maximum, 2.65 and minimum, 0.77 ; ash, maximum, 7.49 and minimum, 0.97 ; maximum of water by direct determination, 23.1 7 and minimum, 8.o ; maximum of specific gravity, 0.9124 and minimum, 0.9093 ; maximum refractive index, I.46I9 and minimum, I.4600; the maximum Reichert-Meissl value, 31.82 and the minimum, 25.42. The highest Crismer value was $54.80^{\circ}$, the lowest, $43.2^{\circ}$; the highest Valenta value was $50^{\circ}$, the lowest, $33.5^{\circ}$; the highest acid figure was $\mathrm{I} 3.40$, the lowest, 1.72; the highest iodine value was 4I.I 5 , the lowest, 34.20 .

Of particular interest was the water determination, in view of the definition of adulterated butter in the law. Eight of the samples gave results in excess of the maximum limit prescribed by the regulations, as shown by the following table:

On account of the heavy tax imposed upon the manufacturers of adulterated butter by the law, it is desirable that the product of renovated butter factories should be carefully controlled by the persons responsible for their operation, in order that it be kept well within the prescribed limit in content of water. The difficulties in the way of an accurate determination of this constituent in a fatty substance like butter are well known. These difficulties apply both to the sampling and to the determination 
Analysis of Renovated Butters Showlyg a Higher Content of WATER THAN I6 PER CEXT.

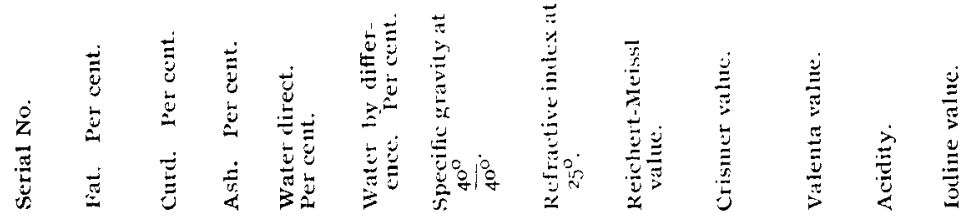

$\begin{array}{llllllllllllll}5735 & 75.64 & \text { I.73 } & 2.95 & 20.62 & \text { 19.68 } & 0.9103 & \text { I. } 4605 & 30.99 & 48.8^{\circ} & 42.0^{\circ} & \text { 6. II } & 36.96\end{array}$ $\begin{array}{lllllllllllll}5795 & 77.12 & 0.77 & 0.97 & 20.32 & 21.14 & 0.9108 & 1.4603 & 30.13 & 47.68^{\circ} & 42.5^{\circ} & 7.30 & 34.70\end{array}$

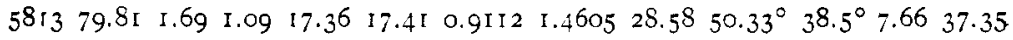
$\begin{array}{llllllllllllllll}5877 & 78.34 & \text { I.52 } & 2.8 & \text { I } 8.0 \text { I } & 17.3 \text { I } & 0.9104 & \text { I. } 46 \text { I } 7 & 26.52 & 49.68^{\circ} & 42.0^{\circ} & 6.04 & \ldots\end{array}$ $\begin{array}{lllllllllllllll}5902 & 77.44 & \text { I.20 } & 2.08 & 20.07 & \text { I } 9.28 & 0.91 \text { II } & \text { I. } 4608 & 29.49 & \ldots & \ldots & \ldots & \ldots & \ldots\end{array}$

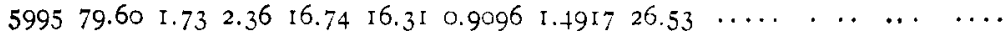
$\begin{array}{lllllllllllllll}6006 & 68.80 & 2.47 & 6.29 & 23.17 & 22.44 & \ldots & 1.4613 & 28.48 & \ldots & \ldots & \ldots & \ldots & \ldots\end{array}$

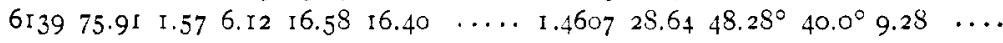

itself. While the average figures for the direct and indirect estimation as given above are in very close agreement, the table of analyses shows a very wide difference in both directions. In several samples, the percentages by the two clifferent methods are over I per cent. apart, and one varies hy i.jo per cent. The direct estimation by drying was used in all cases in passing upon the classification of the butter.

TESTS FOR RFNOYATED BUTTER.

The behavior of each sample uncler the different tests which have been suggested for the identification of renovated butter was studiecl. The tests used were: First, the appearance of the fat when viewed by polarized light (Brown-Taylor-Richards test for melted fat) $;^{1}$ second, the behavior of the fat when boiled in an open vessel (generally known as the "spoon test"); and third, the granulation or "gathering" of the fat when cooled in milk (Waterhouse test).

These tests are described in the methods of the Association of Official Agricultural Chemists, and the last-named especially is quite fully discussed by Patrick, in the proceedings of the same association for Igor, p. I 26, and made applicable to household conditions for detecting oleomargarine, in Farmer's Bulletin, No. I3I, of the U. S. Department of Agriculture. Applied to the above known samples of renovated butter, all the tests failed to give positive results in one or more instances.

t See This Jonrnal 22, $703(1900)$ 
No. 6044 did not respond to the Waterhouse test, and No. 5736 failed with the spoon test, while several of the samples did not give positive indications of melted fat under the microscope. Of the three, the Waterhouse test was found most reliable and definite in its indications. The principle of this test has been used by a recent writer as the basis of a quantitative separation of butter from oleomargarine. ${ }^{1}$

Hess and Doolittle ${ }^{2}$ differentiate between fresh and renovated butter by the character of the curd. Their qualitative test, based upon the appearance of the separated curd, has given no satisfaction whatever in this laboratory; and no work has been done upon their quantitative distinction based upon the relation of casein to albumins.

EXPERIMENTS TO DETERMINE CHANGES BROUGHT ABOUT IN BUTTERFAT BY AERATION.

Having in mind the very radical changes brought about in oils by the process of "blowing," or oxidation, I thought it would not be difficult to establish differences in the composition of butter-fat brought about by the aëration to which it is subjected in the process of renovation. Either because lower temperatures are maintained, however, or for other reasons, no decided changes appear to be produced, and the results of the few experiments I have been able to make in this direction are negative. I will detail them here, however, hoping the matter may be further investigated by others:

A sample of high-grade creamery butter was purchased early in the summer and a portion of it was subjected to analysis. It was then freely exposed to the atmosphere of the laboratory, and even inoculated with rancid butter to hasten its deterioration. It was kept under these conditions throughout the summer, about three months, at the end of which period it had greatly deteriorated, but was not nearly so rancid or offensive as might have been expected. A portion was again taken for analysis and the remainder was melted, and the fat subjected to the process of renovation, as nearly as it could be approximated in the laboratory. The aëration could not be very well carried out, however, and the final result was not very satisfactory, so far as the practical im-

1 Deguide: J. Pharm. Chim., 16, 372 (1902); Abs. J. Soc. Chem. Ind., 21, 1352 (J902).

2 This Journal, 22, I50 (I900). 
provement of the flavor of the fat was concerned. No attempt was made to rechurn the butter, and the last analysis was made upon the renovated fat. The results of the three analyses are given in the following table:

SERIAL No. 4975

\begin{tabular}{|c|c|c|c|}
\hline Fat, per cent $\ldots \ldots \ldots \ldots \ldots \ldots \ldots$ & $\begin{array}{l}\text { Fresh. } \\
88.81\end{array}$ & $\begin{array}{c}\text { After having } \\
\text { become rancid. } \\
88.70\end{array}$ & $\begin{array}{c}\text { After } \\
\text { renovation. } \\
\ldots .\end{array}$ \\
\hline 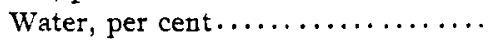 & 8.07 & 7.17 & $\cdots$ \\
\hline 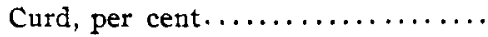 & 1.16 & 1.36 & $\cdots$ \\
\hline \multirow[t]{2}{*}{ Ash, per cent $\ldots \ldots \ldots \ldots \ldots \ldots \ldots$} & I.96 & 2.77 & $\ldots$ \\
\hline & 100.00 & 100.00 & $\ldots$ \\
\hline \multicolumn{4}{|l|}{ Values for fat. } \\
\hline Specific gravity at $\frac{40^{\circ}}{40^{\circ}} \mathrm{C} \ldots \ldots \ldots$ & 0.9106 & 0.9117 & 0.9117 \\
\hline Refractive index at $25^{\circ} \mathrm{C} \ldots \ldots \ldots$ & . $\quad 1.4612$ & 1.4613 & I. 4614 \\
\hline Reichert-Meissl value $\ldots \ldots \ldots \ldots$ & 27.97 & 27.27 & 27.46 \\
\hline 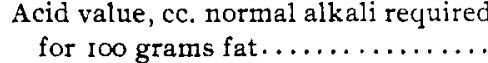 & $\ldots$ & 4.28 & 4.28 \\
\hline Hehner value $\ldots \ldots \ldots \ldots \ldots \ldots$ & 88.94 & 85.43 & 85.23 \\
\hline Valenta value................. & $44.75^{\circ}$ & $49 .^{\circ}$ & $48 .^{\circ}$ \\
\hline Crismer value ................ & $58.5^{\circ}$ & $49.7^{\circ}$ & $49.7^{\circ}$ \\
\hline Saponification value $\ldots \ldots \ldots \ldots \ldots$ & $.217 \cdot 3$ & $217 \cdot 3$ & 214.8 \\
\hline Soluble fatty acids, per cent ....... & - $4.6_{3}$ & $3 \cdot 77$ & 3.89 \\
\hline
\end{tabular}

It will be seen that the fat values of the butter after renovation differ less from those of the butter before renovation than the latter differ from the values of the fresh butter. ${ }^{1}$

Through the courtesy of a firm of local manufacturers, an opportunity was offered to take samples of butter before and after renovation in the regular work of the factory. Two sets of samples were taken on two different days; it was not found possible to make the samples all strictly comparative on account of the difficulty of sampling the material in solid form, and for other reasons. The samples of butter-fat before and after blowing, however, are believed to be very closely comparable, having been taken from a single vessel containing a large quantity of the material, the one before, and the other after it had been subjected to the aërating process.

The following table gives the results obtained:

1 Compare this Journal, 24, 71 (1902). 
Second
Experiment.

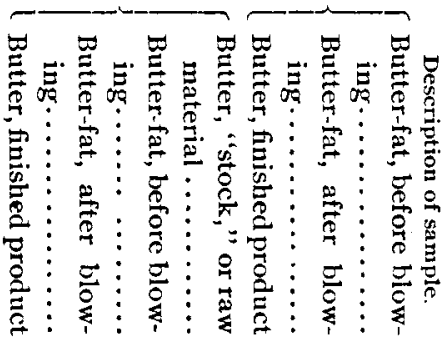

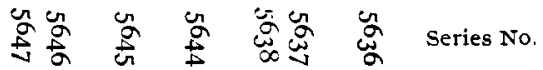

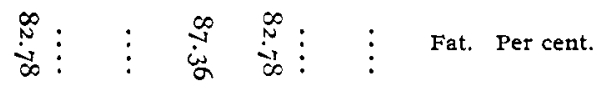

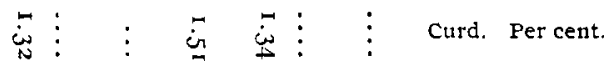

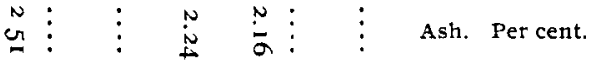

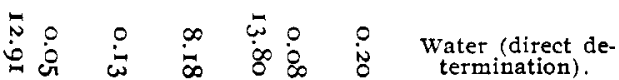

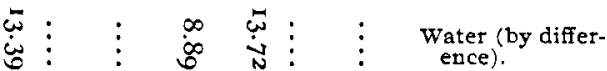

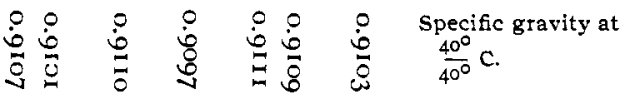

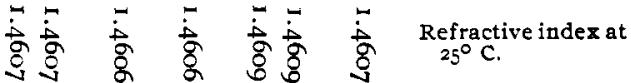

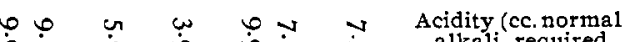

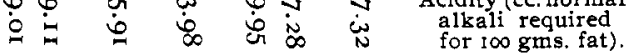

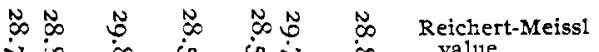

$\dot{\gamma} \dot{\infty} \infty$ in

虽

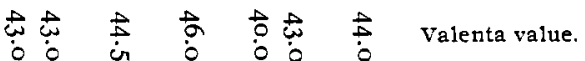

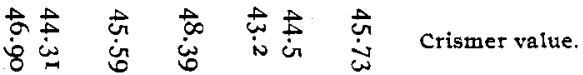

嵌岁

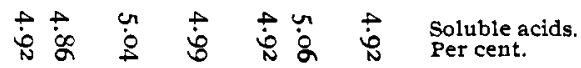


The greatest variation in any of the values obtained from the butter-fat is shown by the Reichert-Meissl value. In the first series of samples, the Reichert-Meissl value of the fat is higher after blowing than before, while in the second series it is just the reverse. I am unable to account for this. The variations in the other values are slight, and no definite conclusion can be drawn from them. Apparently the differences in the composition of butter-fat brought about by renovation, if any, are minute, and a long series of comparative analyses would be necessary to develop them.

For the present, reliance must be placed upon the physical tests for melted fat, as previously detailed.

I am indebted to Messrs. Simons, Adams, and Law, assistants in the laboratory, by whom the analytical work was performed.

[CONTRIbUtions from the SHeffiet.d Laboratory of Yale UniverSITY.]

ON SOME ALDEHYDE CONDENSATION PRODUCTS OF ARYLPSEUDOTHIOHYDANTOINS.

BY HENRY L. WhEELER AND GEORGE S. JAMIESON.

Received January 23, 1902.

IN the course of our ${ }^{1}$ work on the molecular rearrangement of thiocyanacetanilides it was found that certain stable pseudothiohydantoins gave diacetyl derivatives when warmed with acetic anhydride, and it was shown that these acetyl compounds did not behave like acetoacetic acid derivatives. This would seem to indicate that the group $-\mathrm{CO}-\mathrm{CH}_{2}-\mathrm{S}-$ is not present in the stable pseudothiohydantoins.

It has been shown, however, by Andreasch ${ }^{2}$ that the nonsubstituted pseudothiohydantoin condenses with benzaldehyde and behaves like other ${ }^{3}$ compounds which contain the above group; and we have now found that substituted pseudothiohydantoins, which are to be represented by formulas I, II and III, are also capable of condensing with aldehydes and with oxalic ester. The stable pseudothiohydantoins (I) therefore behave in a

1 wheeler and Johnson: $A \mathrm{~m}$. Chem. J., 28, ini (1902).

2 Monatsh. Chem., 8, 407.

3 Loven: Ber. d. chem. Ges., 18, 3242 (1885); Nencki and Sieber : Ibid., 17, 2278 (1884); Ginsberg and Bondzynski : Ibid., 19, ing (1886); Monatsh. Chem., 8, 358 (188;); Andreasch: lbid., 8, 407, 10, 75 (1889). 